\title{
Seasonal control of penile development of Siberian hamsters (Phodopus sungorus) by daylength and testicular hormones
}

\author{
J. H. Park' ${ }^{1}$, E. M. Spencer ${ }^{2}$, N. J. Place ${ }^{1}$, C. L. Jordan ${ }^{3}$ and I. Zucker ${ }^{1,4}$ \\ ${ }^{1}$ Department of Psychology and ${ }^{4}$ Department of Integrative Biology, University of California, \\ Berkeley, CA 94720, USA; ${ }^{2}$ California Pacific Medical Center, San Francisco, CA 94114, USA; \\ and ${ }^{3}$ Department of Psychology and Neurosciences Program, Psychology Research Building, \\ Michigan State University, East Lansing, MI 48824, USA
}

Seasonal variation in prepubertal penile growth has not previously been studied. The present study assessed the influence of daylength and androgens on penile development in the Siberian hamster (Phodopus sungorus). Adult penile masses were achieved at 18 and 8 weeks of age in hamsters maintained from birth under short $(10 \mathrm{~h}$ light: $14 \mathrm{~h}$ dark) versus long (14 $\mathrm{h}$ light:10 $\mathrm{h}$ dark) daylengths, respectively. Insulin-like growth factor I concentrations, previously implicated in penile growth, did not differ between hamsters maintained in short versus long daylengths. Gonadectomized juvenile males maintained in short and long daylengths and administered testosterone attained adult penile masses well in advance of untreated gonadintact males maintained in short daylengths. Hamsters from both photoperiods, castrated as juveniles and first treated with testosterone in adulthood, also achieved adult penile masses. The photoinhibited gonad is insufficient to promote penile growth, and prepubertal gonadal secretions during short daylengths are not necessary for eventual penile development. Among young born near the end of the mating season, onset of neuroendocrine refractoriness to short daylengths at about 100 days of age and subsequent gonadal development induces growth in all reproductive tissues. Timing of puberty and increased androgen secretion controlled by daylength are the primary determinants of postnatal penile growth, which may also be affected by prenatal and early postnatal organizational actions of androgens.

\section{Introduction}

Testicular androgens influence mammalian penile growth during fetal development and peri-pubertally (Williams-Ashman, 1990). Penile growth ceases on completion of puberty in humans and rats (Gonzalez-Cadavid et al., 1991). Phallic size is substantially smaller in hypogonadal individuals or those castrated prepubertally than in normal individuals. A very short penis is a major cause of deficits in the mating behaviour of rats deprived of testicular androgens early in life; penile length and mass are highly correlated (Beach et al., 1969; Hart, 1974). In addition to androgens, insulin-like growth factor I (IGF-I) has been implicated in penile growth on the basis of clinical reports (McMahon et al., 1995; Laron and Klinger, 1998; Laron, 1999; Le Roith et al., 2001a,b) and in vitro studies (Liu et al., 2001). The mechanisms by which exogenous IGF-I treatment affects penile growth are enigmatic (Butler and Le Roith, 2001; Le Roith et al., 2001a,b).

Previous animal models of mammalian penile development have been restricted to species that do not show seasonal variations in onset of puberty. Variation

Email: jhp@socrates.berkeley.edu in daylength profoundly affects the timing of sexual maturation of temperate zone mammals (Foster et al., 1988; Ebling and Cronin, 2000; Gorman et al., 2001; Prendergast et al., 2002). In rodents, offspring born before and after the summer solstice typically reach puberty at approximately 5 weeks and 5 months of age, respectively (Horton, 1984a,b; Gorman and Zucker, 1998). To the authors' knowledge, the timing of penile growth and the influence of seasonal differences in daylength on phallic development have not been assessed in any seasonally mating mammal. The present study sought to specify how timing of birth within an extended mating season and hormones interact to control development and maintenance of reproductive structures in the Siberian hamster (Phodopus sungorus).

Androgen concentrations in the Siberian hamster are comparable on day 5 after birth in males housed under either a short-day (SD) or long-day (LD) photoperiod; after day 20, however, SD males maintain low basal androgen concentrations for several months, whereas concentrations increase markedly in LD animals (Yellon and Goldman, 1984). Low androgen concentrations sustained by SD prepubertal male Siberian hamsters restrain gonadotrophin secretion (Simpson et al., 1982), but neither support growth of the seminal vesicles and ventral 
prostate glands (Schindelmeiser et al., 1988) nor induce spermatogenesis (Hoffmann, 1978); their effect on penile growth has not been assessed.

It is not known whether the reduced androgen concentrations sustained by the immature testes of hamsters housed under short daylengths support penile development before puberty, or influence penile growth rates at the time of puberty. Organizational actions of androgens secreted by the fetal and early postnatal testis may be necessary to induce subsequent penile responsiveness to testosterone and $5 \alpha$-dihydrotestosterone. The present study assessed whether the reduced steroidogenic activity of the SD testes is sufficient to sustain moderate penile growth, even if complete reproductive development awaits pubertal increases in androgen secretion. The Siberian hamster is a useful model system for investigating the interactions of pre- and postnatal androgens and environmental factors in penile development.

\section{Materials and Methods}

\section{Animals}

Siberian hamsters (Phodopus sungorus) from the local mating colony were descended from stock supplied by K. Wynne-Edwards (Queen's University, Kingston, Ontario). Males were gestated and maintained under either a SD photoperiod (10 h light:14 h dark) or a LD photoperiod ( $14 \mathrm{~h}$ light:10 h dark). Hamsters were weaned at either 15 or 18 days of age and then housed individually in polypropylene cages $(25 \mathrm{~cm} \times 14 \mathrm{~cm} \times$ $12 \mathrm{~cm}$ ). Food (Purina rodent chow 5015) and water were provided ad libitum, and an ambient temperature of $22 \pm 2{ }^{\circ} \mathrm{C}$ was maintained. All procedures were approved by the Animal Care and Use Committee of the University of California at Berkeley (Protocol R-084).

\section{Experiment 1}

Male hamsters, gestated and maintained under either a SD or LD photoperiod, and weaned at 18 days of age, were killed at 20,40,60,80,100, 120 or 140 days of age ( $n=10$ per group except for SD animals at 80 and 120 days of age $(n=7)$ and LD hamsters at 120 days of age $(n=9))$. One LD male at 120 days of age was considered an outlier as it had undeveloped gonads (paired testes mass of $17.2 \mathrm{mg}$ compared with mean paired testes mass of $565.0 \mathrm{mg}$ for the other males in the group). Data pertaining to this hamster were excluded from the statistical analyses. Radioimmunoassay of IGF-I was performed for samples taken from animals at 20,40, 60 and 140 days of age ( $n=5$ per group).

\section{Experiment 2}

LD males were castrated $(n=11)$ or sham-castrated $(n=10)$ at 15 days of age and provided with blank Silastic capsules (Dow Corning, Midland, Ml; inner dia- meter $1.98 \mathrm{~mm}$, outer diameter $3.18 \mathrm{~mm}$ ); a third group of males $(n=8)$, also castrated at day 15 , received capsules filled with testosterone. SD males were treated in a similar way ( $n=7$ for each group). Tissues were harvested and blood samples were collected at 80 days of age.

\section{Experiment 3}

LD and SD males were castrated at 15 days of age and either given a blank capsule $(n=8$ and $n=3$, respectively) or a testosterone-filled capsule ( $n=6$ and $n=3$, respectively) at 80 days of age. Other $\operatorname{LD}(n=9)$ and SD $(n=5)$ males were sham-castrated at 15 days of age and provided with a blank capsule at 80 days of age. Tissues were harvested and blood samples were collected at 140 days of age.

\section{Experiment 4}

LD males were sham-castrated $(n=9)$ or castrated $(n=8)$ and administered a blank capsule at 80 days of age, or castrated $(n=9)$ and given a testosterone-filled capsule at 80 days of age. Tissues were extracted and blood samples were collected at 140 days of age.

\section{Surgical procedures}

Male hamsters were anaesthetized with an i.p. injection of a ketamine mixture $\left(21.0 \mathrm{mg}\right.$ ketamine $\mathrm{ml}^{-1}$, $2.4 \mathrm{mg}$ xylazine $\mathrm{ml}^{-1}, 0.3 \mathrm{mg}$ acepromazine $\mathrm{ml}^{-1}$; $0.34 \mathrm{ml}$ per $100 \mathrm{~g}$ body weight) before castration and tissue extraction. Castrations were performed via a midline incision; the testicular artery was ligated; the testis was excised and the wound closed with sterile sutures. Hamsters were injected s.c. with the analgesic $5 \%$ buprenorphine $(0.05 \mathrm{ml}$ per animal), after surgery.

Tissues were extracted between 13:00 $\mathrm{h}$ and 17:00 $\mathrm{h}$. Body weight was recorded $( \pm 0.1 \mathrm{~g})$ and the penis, testes, seminal vesicles (fluid not drained) and ventral prostate glands were removed under a dissecting microscope and weighed $( \pm 0.01 \mathrm{mg})$. Surrounding subcutaneous tissue was removed before dissecting the penis at the base of the shaft adjacent to the pubic bone. When the fluid of the seminal vesicles was drained, mass values similar to those found by Anand et al. (2002) were obtained (J. H. Park, unpublished). Trunk blood was collected between 13:00 $\mathrm{h}$ and 17:00 $\mathrm{h}$ for subsequent determination of concentrations of IGF-I and testosterone.

\section{Hormone replacement}

Silastic capsules (Dow Corning) were filled to a length of $4 \mathrm{~mm}$ with crystalline testosterone (Sigma, St Louis, MO), and the ends of the capsules were sealed with silicon rubber cement. Hormone-filled capsules of this size generate serum concentrations of testosterone 
similar to those recorded in gonad-intact male Siberian hamsters (Bartness, 1995; Mauer and Bartness, 1995). Blank capsules were prepared in a similar way, but were left empty. Blank and testosterone-filled capsules were incubated separately in saline for $24 \mathrm{~h}$ before insertion. Capsules were placed s.c. in the interscapular area via a small incision that was closed with a wound clip. Hamsters were anaesthetized with isoflurane vapour (Aerrane; Fort Dodge Animal Health, Fort Dodge, IA) before implantation of the capsules.

\section{Non-responder exclusions}

Whereas the majority of Siberian hamsters maintained under short photoperiods retain small undeveloped testes until at least 100 days of age, a minority fail to develop the typical SD phenotype, and instead undergo rapid and substantial testicular growth in short daylengths (Hoffmann, 1978, 1982). Hamsters with paired testes masses above $100 \mathrm{mg}$ were judged to be unresponsive to the short daylength (Gorman, 2001), and data pertaining to these hamsters were excluded from the statistical analyses.

\section{IGF-I radioimmunoassay}

Serum aliquots (about $200 \mu \mathrm{l}$ ) were centrifuged at room temperature $\left(22 \pm 2^{\circ} \mathrm{C}\right)$ for $20 \mathrm{~min}$ at $664 \mathbf{g}$, and the serum was collected and frozen at $-80^{\circ} \mathrm{C}$ until assayed for IGF-I or testosterone by radioimmunoassay. Before radioimmunoassay, IGF-I was separated from IGFbinding proteins by chromatography on a $1 \times 110 \mathrm{~cm}$ Sephadex G-50 column equilibrated with 1 mol acetic acid $\mathrm{I}^{-1}$. The IGF-I peak was dried by a Speed-Vac (Savant Instruments, Farmingdale, NY), then reconstituted in assay buffer $(50 \mathrm{mmol}$ basic sodium phosphate $\mathrm{I}^{-1}, 0.1 \% \mathrm{NaCl}, 0.1 \%$ EDTA, $0.1 \%$ sodium azide, $0.02 \%$ protamine sulphate and $0.05 \%$ Tween-20 adjusted to pH 7.5 with $\mathrm{NaOH}$ ). The IGF-I peak was analysed using a heterologous radioimmunoassay described by Chan and Spencer (1998). The assay used anti-rat IGF-I antiserum and human IGF-I as standard and trace. The radioimmunoassay was performed at $4{ }^{\circ} \mathrm{C}$ for $16-20 \mathrm{~h}$ in polypropylene tubes containing $200 \mu \mathrm{l}$ standard (human IGF-I) or diluted sample in assay buffer, $200 \mu \mathrm{l}$ first antibody diluted 1:60000 and $200 \mu \mathrm{l}$ trace containing 10000 c.p.m. [ $\left.{ }^{125} \mathrm{l}\right] \mathrm{hlGF}-\mathrm{l}$. After incubation, $100 \mu \mathrm{l}$ $1: 15$ dilution of goat anti-rabbit $\gamma$-globulin, $100 \mu$ l 1:200 dilution of rabbit $\gamma$-globulin and $0.7 \mathrm{ml} \mathrm{9.14 \%}$ polyethylene glycol 8000 (Sigma; pH 7.3) were added and mixed. After $15 \mathrm{~min}$, the samples were centrifuged at $3000 \mathrm{~g}$ for $30 \mathrm{~min}$ at $4{ }^{\circ} \mathrm{C}$, and the radioactivity of the pellets was counted on a Berthold Gamma Counter LB 2104 (Wallac Inc., Gaithersburg, MD). The nonspecific binding was less than $1 \%$ and the specific binding of tracer was $35-50 \%$. The intra- and interassay coefficients of variation were 3.6 and $5.6 \%$, respectively.
The assay was validated for Siberian hamster serum by demonstrating parallel dilution to the standard in the radioimmunoassay.

\section{Testosterone radioimmunoassay}

Testosterone was measured using a solid-phase ${ }^{125}$ I radioimmunoassay kit (Diagnostic Systems Laboratories, Webster, TX). Serum samples were divided into $50 \mu \mathrm{l}$ aliquots into duplicate assay tubes and incubated with tracer for $1 \mathrm{~h}$ at $37^{\circ} \mathrm{C}$. Crossreaction of the testosterone antibody to $5 \alpha$-dihydrotestosterone was $5.8 \%$, and the lower limit of detection was $0.08 \mathrm{ng} \mathrm{ml}^{-1}$, as reported by the manufacturer. Hamster samples containing testosterone concentrations greater than the upper limit of detectability of the assay ( $25 \mathrm{ng} \mathrm{ml}^{-1}$ ) were re-assayed after diluting with the serum blank provided. A dilution curve of pooled hamster serum was parallel to the standard curve of the kit. Testosterone was not detected in charcoal-stripped hamster serum. Spiking the stripped and pooled serum samples with a known amount of testosterone yielded values that were within $10 \%$ of the values expected. Intra- and interassay coefficients of variation were 6.0 and $8.4 \%$, respectively.

\section{Statistical analysis}

One-way ANOVA was used to analyse body and tissue masses and hormone concentrations. Plasma samples with undetectable testosterone concentrations were assigned the minimal detectable value of the assay $\left(0.08 \mathrm{ng} \mathrm{ml}^{-1}\right)$, and any samples that were re-assayed after diluting with the serum blank that still had testosterone values greater than three standard deviations from the mean were omitted from statistical analyses. Post hoc comparisons were conducted using the Fisher protected least significant difference test where appropriate (Statview 5; SAS Institute, Cary, NC). Observed differences were considered significant if $P<0.05$.

\section{Results}

\section{Experiment 1: impact of daylength on development}

Penile development and body weight. Males maintained under the LD photoperiod underwent substantial penile growth between 20 and 40 days of age (from $16.7 \pm 0.6$ to $38.7 \pm 1.2 \mathrm{mg}$; Fig. $1 \mathrm{a}$ ). Adult penile masses were attained by 60 days, with no subsequent change at later ages. In sharp contrast, penile mass was arrested in males maintained in the SD photoperiod; low values of $12-15 \mathrm{mg}$ were sustained from 20 to 100 days of age (Fig. 1a). Between 100 and 120 days of age, penile mass increased from $17.0 \pm 3.7$ to $45.7 \pm 2.1 \mathrm{mg}$, similar to the growth seen in LD males between 20 and 40 days of age. At 120 and 140 days of age, penile masses were equivalent in SD and LD males. 
(a)

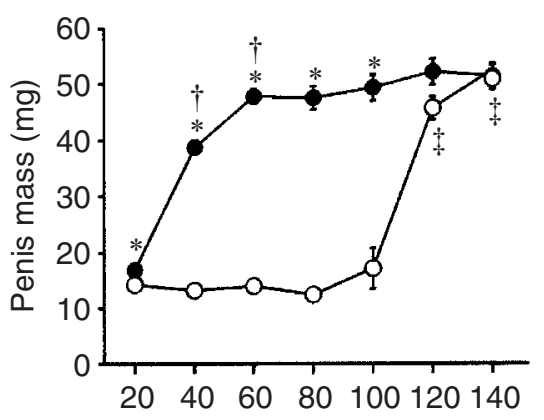

(c)

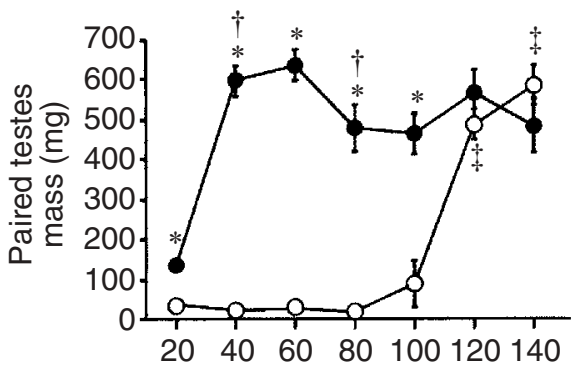

(e)

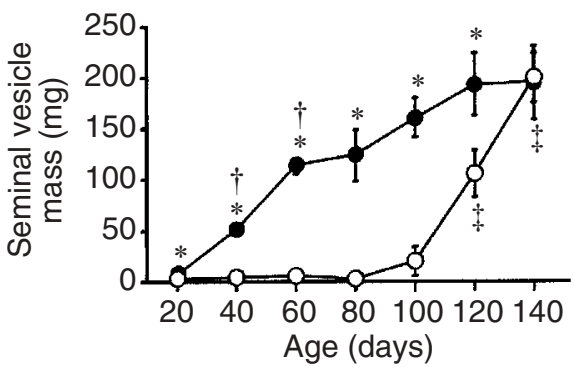

(b)

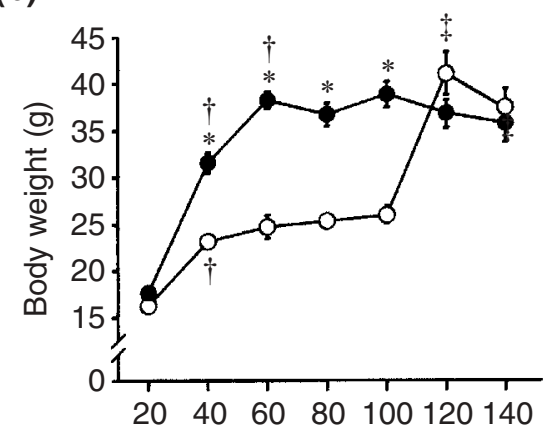

(d)

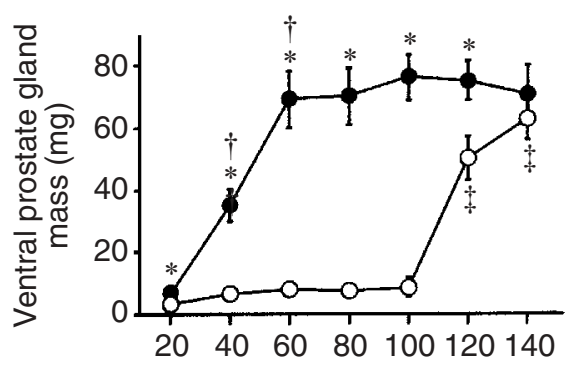

(f)

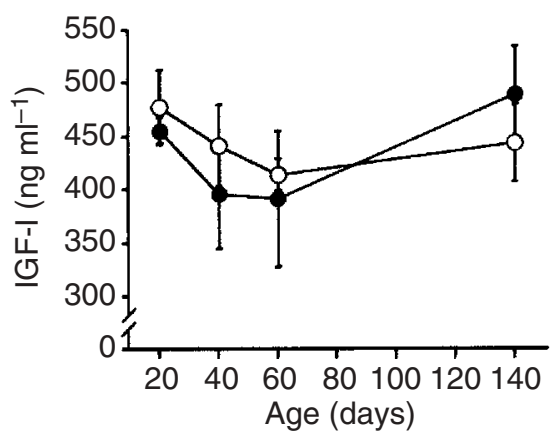

Fig. 1. Mean \pm SEM masses of (a) penis, (b) body, (c) paired testes, (d) ventral prostate gland and (e) seminal vesicle, and (f) insulin-like growth factor I (IGF-I) concentration of Siberian hamsters kept under long $(\mathrm{LD}, \mathbf{0})$ and short $(\mathrm{SD}, \mathrm{O})$ daylengths throughout gestation and after birth. ${ }^{*}$ Significantly different values $(P<0.05)$ for LD versus SD groups; ${ }^{\dagger}$ significant difference $(P<0.05)$ within LD groups from previous time point; and ${ }^{\ddagger}$ significant difference $(P<0.05)$ within SD groups from previous time point.

The increase in penile mass in SD males between 100 and 120 days of age $(169 \%)$ greatly exceeded the increment in body weight (58\%). Similarly, the penile growth spurt in LD males from 20 to 40 days of age, a $132 \%$ increase, also exceeded the $78 \%$ increase in body weight during this period. Body weights did not differ between LD and SD males at 20 days of age but were significantly greater in the former group from 40 to 100 days of age (Fig. 1b). Adult body weights were attained by 60 and 120 days of age, respectively, by the LD and SD males.

Testes masses. Changes in paired testes masses closely mirrored those for penile masses. The gonads of LD males grew markedly from 20 to 40 days of age, whereas those of SD males remained undeveloped to 100 days of age and grew rapidly to attain adult masses by 120 days in parallel with penile growth in these same animals (Fig. 1c).

Ventral prostate gland and seminal vesicles. LD males attained adult ventral prostate gland masses by 60 days of age (Fig. 1d), similar to that for the penis, testes and body masses. Ventral prostate gland growth was markedly delayed in SD hamsters; adult status was achieved at 140 days of age (Fig. 1d). 
(a)

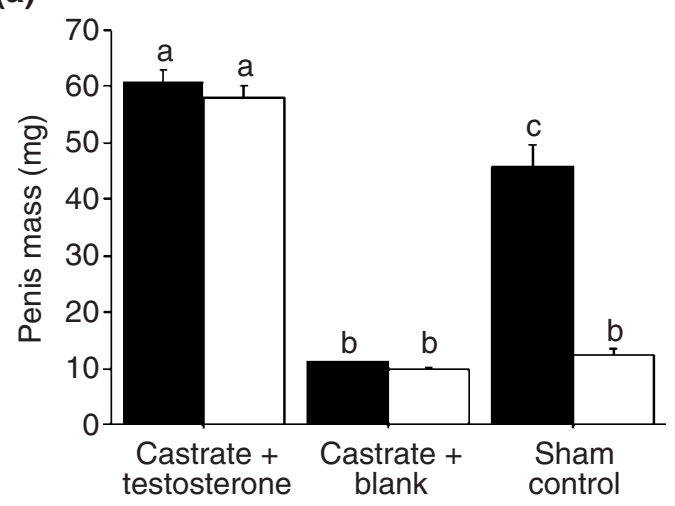

(c)

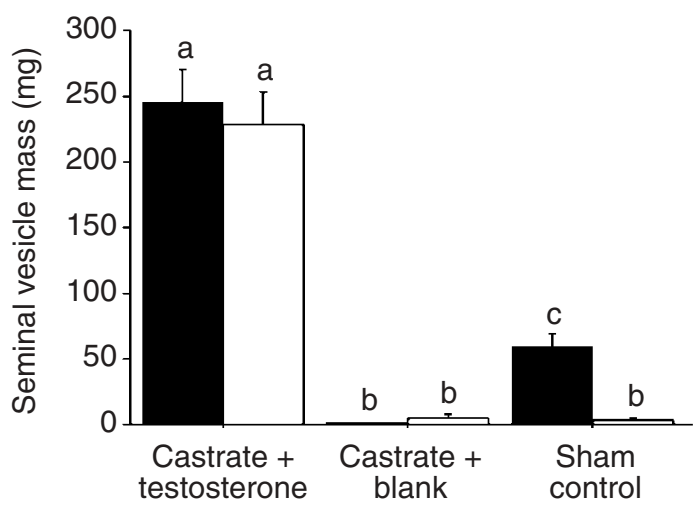

(b)

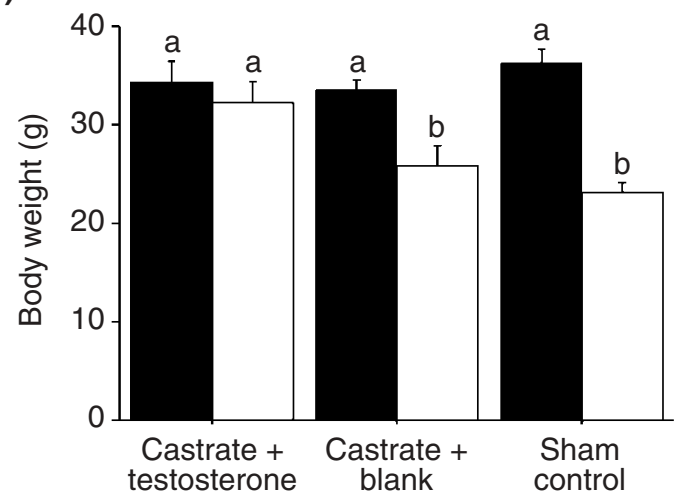

(d)

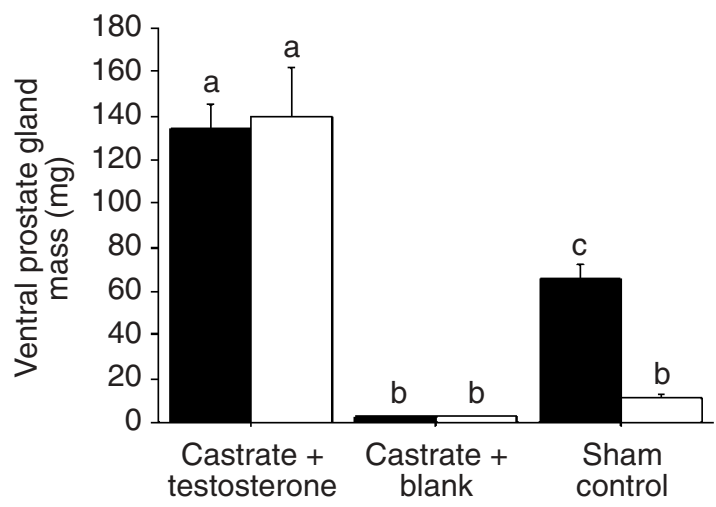

(e)

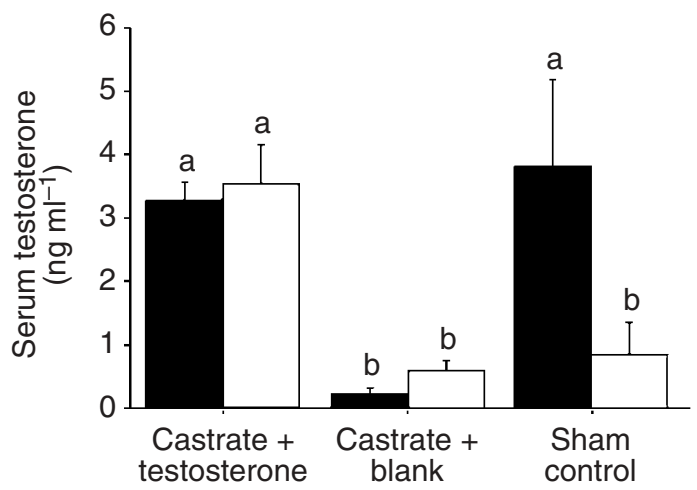

Fig. 2. Mean \pm SEM masses of (a) penis, (b) body, (c) seminal vesicle and (d) ventral prostate gland, and (e) serum testosterone concentration at 80 days of age of Siberian hamsters kept under long (घ) and short ( $\square$ ) daylengths throughout gestation and after birth. Males were castrated and given either a testosterone-filled or blank capsule at 15 days of age, or sham-castrated and given a blank capsule at 15 days of age. abcBars with different letters differ significantly from each other $(P<0.05)$.

Seminal vesicle masses of LD males increased in a gradual almost linear manner from 20 to 120 days of age (Fig. 1e). The accelerated growth spurt at about 40 days of age, characteristic of all other tissues sampled, was not in evidence. In contrast, the growth pattern of the seminal vesicles of SD males was comparable to that for other androgen-dependent tissues and occurred between 100 and 140 days of age (Fig. 1e).

IGF-I. Blood concentrations of this hormone did not differ between LD and SD males at any age and also did not change with age (Fig. 1f). 
(a)

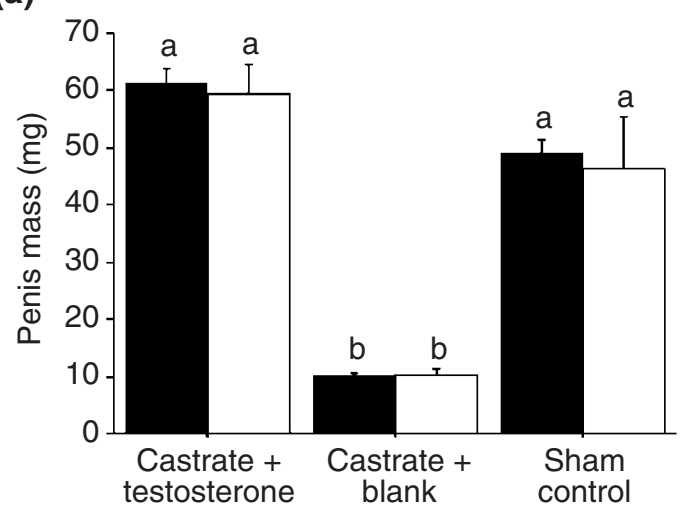

(c)

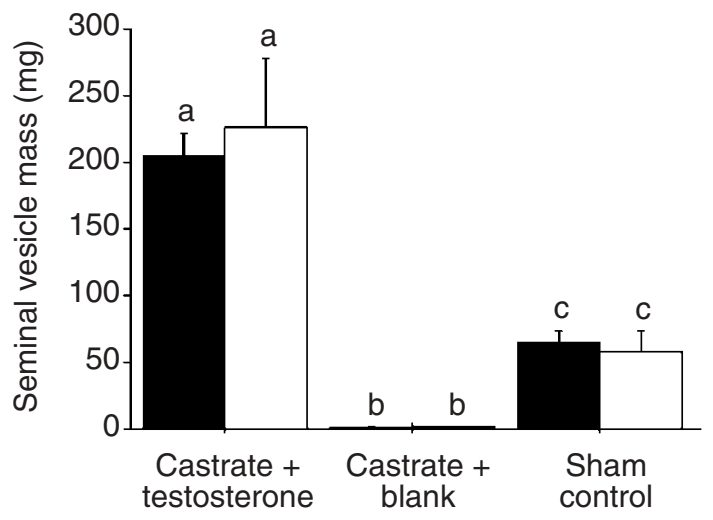

(e)

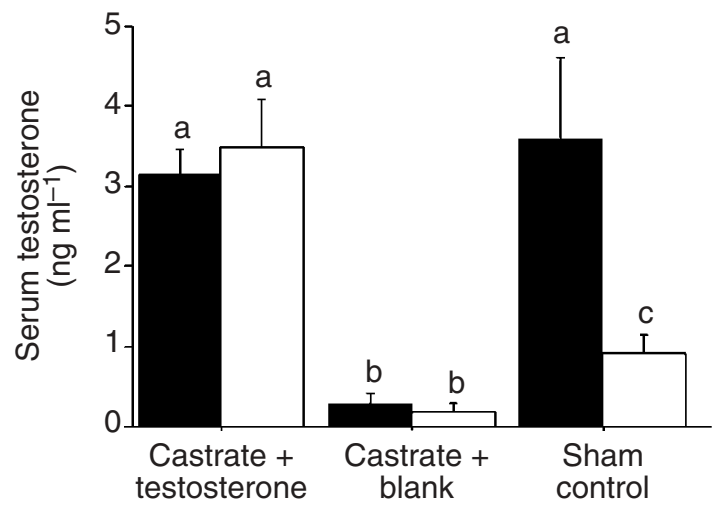

(b)

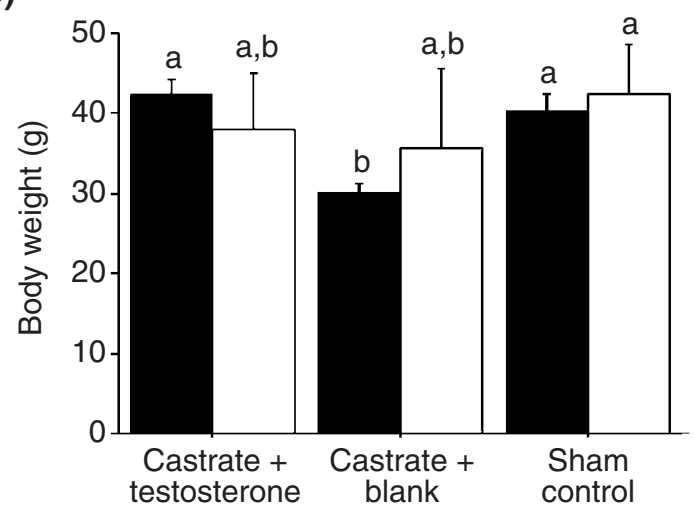

(d)

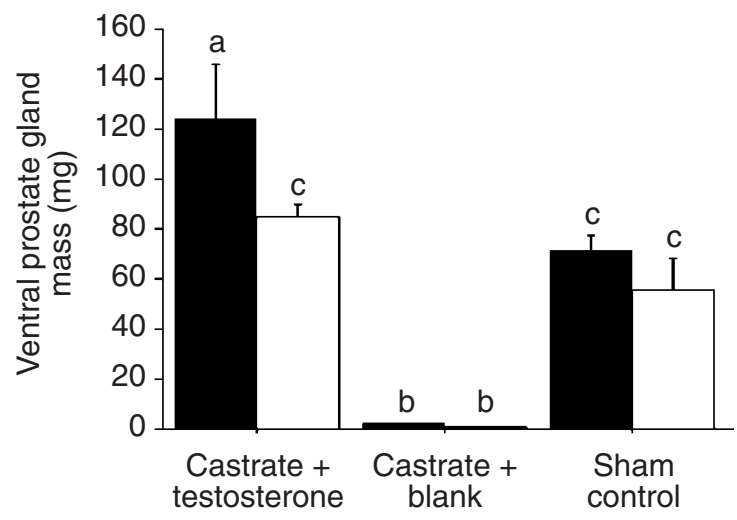

Fig. 3. Mean \pm SEM masses of (a) penis, (b) body, (c) seminal vesicle and (d) ventral prostate gland, and (e) serum testosterone concentration at 140 days of age of Siberian hamsters kept under long ( $(\mathbf{\square})$ and short $(\square)$ daylengths throughout gestation and after birth. Males were castrated at 15 days of age and given either a testosterone-filled or blank capsule at 80 days of age, or sham-castrated at 15 days of age and given a blank capsule at 80 days of age. ${ }^{a b c}$ Bars with different letters differ significantly from each other $(P<0.05)$.

\section{Experiment 2: impact of prepubertal androgens in short} versus long daylengths

Penile development and body weight. By 80 days of age, the penes of castrated LD and SD males treated with testosterone capsules at 15 days of age had undergone significant growth $(60.8 \pm 2.3$ and $57.8 \pm 2.4 \mathrm{mg}$, respectively), exceeding the penile masses of sham-castrated LD males $(46.1 \pm 3.3 \mathrm{mg}$; Fig. 2a). In hamsters castrated pre-pubertally and not treated with androgen, penile development was arrested to the same extent, regardless of the photoperiod in which they were 
(a)

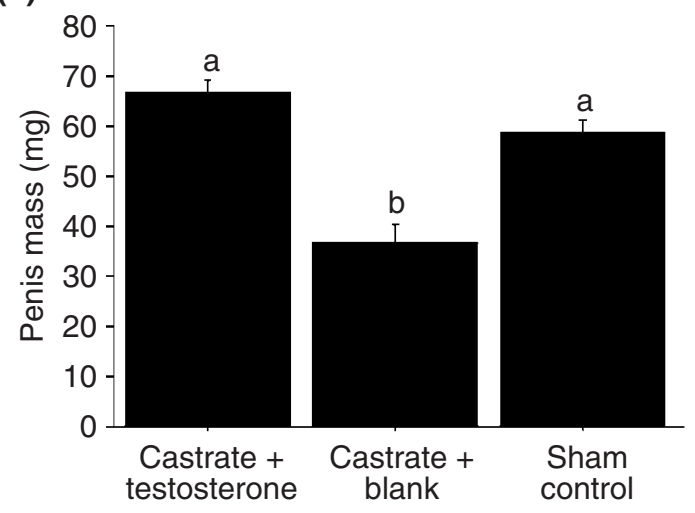

(c)

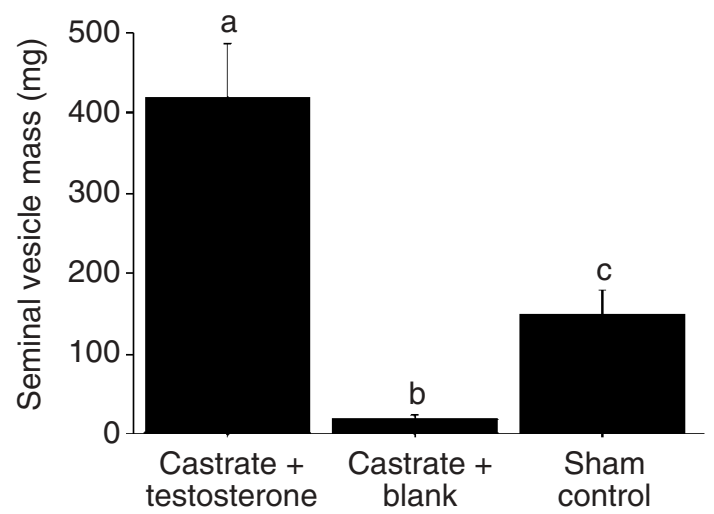

(e)

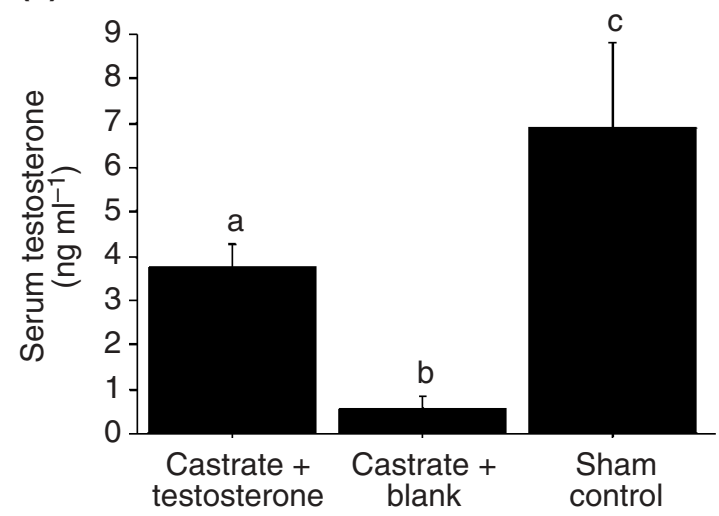

(b)

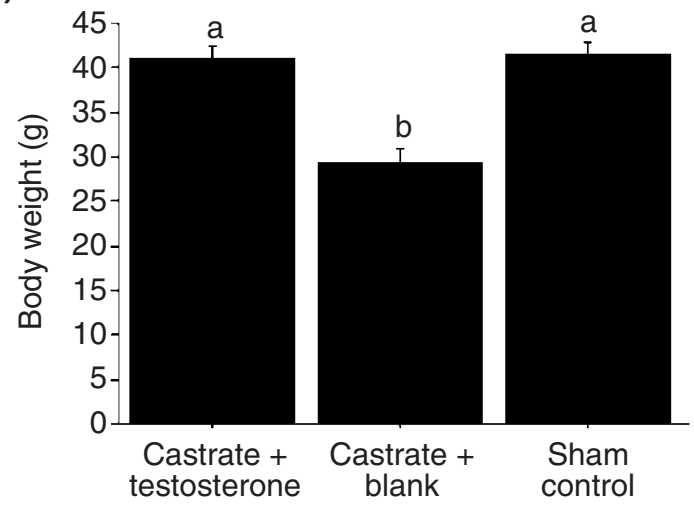

(d)

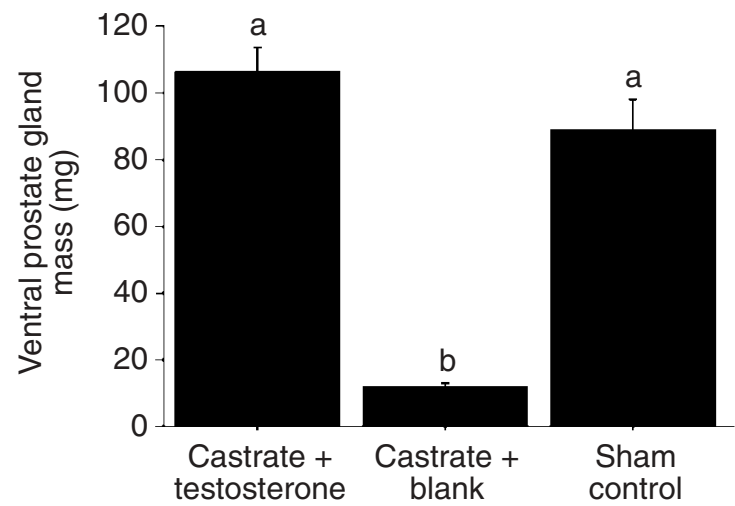

Fig. 4. Mean \pm SEM masses of (a) penis, (b) body, (c) seminal vesicle and (d) ventral prostate gland, and (e) serum testosterone concentration at 140 days of age of Siberian hamsters kept under long daylengths throughout gestation and after birth. Males were castrated and given either a testosterone-filled or blank capsule at 80 days of age, or sham-castrated and given a blank capsule at 80 days of age. ${ }^{a b c}$ Bars with different letters differ significantly from each other $(P<0.05)$.

gestated and subsequently housed. The lack of penile development was similar to that seen in sham-castrated males kept in the short daylength (Fig. 2a). There were no differences in body weight among any of the groups except that the SD-castrated and sham-castrated males weighed significantly less than animals in the other groups (Fig. 2b).
Seminal vesicles and ventral prostate gland. Whereas there was virtually no seminal vesicle or ventral prostate gland growth in the absence of androgens, testosterone administration to castrated LD and SD males resulted in markedly increased seminal vesicle and ventral prostate gland masses compared with values recorded in LD sham-castrated males (Fig. 2c,d). 
Testosterone. Testosterone concentrations were significantly higher in LD sham-control males and in LD and SD males treated with testosterone capsules than in SD sham-control males and LD and SD males treated with empty capsules $(P<0.05$; Fig. $2 \mathrm{e})$.

\section{Experiment 3: impact of androgens in adulthood after juvenile castration}

Penile development and body weight. Males castrated as juveniles and treated with testosterone for two months beginning at 80 days of age achieved adult penile masses comparable with those of sham-operated control animals (Fig. 3a). In the absence of testosterone treatment, penile development was arrested at the juvenile level to 140 days of age. Body weight did not differ among the groups except that the LD castrated males weighed less than the LD castrated males treated with testosterone and SD sham-castrated controls (Fig. 3b).

Seminal vesicles and ventral prostate gland. Two months of exposure to testosterone in adulthood induced massive growth of the seminal vesicles in males castrated as juveniles and maintained in either photoperiod. Seminal vesicle masses of these groups far surpassed those of intact LD and SD controls (Fig. 3c). In the absence of androgen replacement, the seminal vesicles in castrated males under either photoperiod were almost completely undeveloped.

Testosterone treatment in adulthood induced growth of the ventral prostate gland in males castrated as juveniles and maintained in either the long or short photoperiod. Values for these groups did not differ significantly from those of the LD and SD sham controls (Fig. $3 \mathrm{~d}$ ). In contrast, there was virtually no growth of the ventral prostate gland in castrated animals provided with a blank capsule.

Testosterone. Testosterone concentrations were significantly higher in LD sham-control males and in LD and SD castrated males treated with testosterone capsules than in LD and SD castrates treated with empty capsules $(P<0.05$; Fig. 3e). Testosterone concentrations of SD sham-control males were significantly higher than those of both LD and SD castrated males treated with empty capsules $(P<0.05)$, but significantly lower than those of LD sham-control males and LD and SD males treated with testosterone capsules $(P<0.05)$.

\section{Experiment 4: impact of androgens in adulthood}

Penile development and body weight. Penile masses of LD males castrated as adults and treated with testosterone did not differ significantly from those of sham-castrated controls $(P>0.05$; Fig. 4a). Penile masses of males determined 60 days after castration in adulthood were substantially lower than those of intact sham-operated
Controls $(36.7 \pm 3.6$ versus $58.6 \pm 2.8 \mathrm{mg}$, respectively; $P<0.001$; Fig. 4a), as reported by Lerchl et al. (1993). Body weights were similarly affected by castration; castrated males not treated with testosterone manifested a $29 \%$ decline in body weight (Fig. 4b). The $37 \%$ decrease in penile mass attributable to castration was similar to the corresponding decrease in body weight.

Seminal vesicles and ventral prostate gland. The seminal vesicles underwent atrophy in untreated castrated males. In contrast to the other sampled tissues, seminal vesicle masses of hamsters treated with testosterone capsules in adulthood exceeded those of the shamoperated controls ( $420 \pm 67$ versus $148 \pm 31 \mathrm{mg}$, respectively; $P<0.001$; Fig. 4c).

The pattern of change of the ventral prostate gland masses was similar to that for seminal vesicle masses in that the $646 \%$ decrease in ventral prostate gland masses and the $690 \%$ decrease in seminal vesicle masses of untreated castrated versus intact males far exceeded the $42 \%$ decrease in body weights and the $60 \%$ decrease in penile masses (Fig. 4d).

Testosterone. Testosterone concentrations were significantly higher in LD castrates treated with testosteronefilled capsules compared with empty capsules $(P<0.05)$ but significantly lower than those of intact LD shamcontrol males ( $P<0.05$; Fig. $4 \mathrm{e})$.

\section{Discussion}

Daylength profoundly influences penile development in Siberian hamsters. Blood testosterone concentrations of SD males are about $20 \%$ of values in LD males from 20 to 100 days of age. SD testosterone concentrations are sufficient to inhibit gonadotrophin secretion (Simpson et al., 1982), but fall below the threshold required for complete penile development. Failure of prepubertal penile growth in SD males reflects insufficient hormone secretion rather than a lack of tissue responsiveness to hormone, as evidenced by penile growth induced by exogenous testosterone treatment of SD males beginning at 15 days of age. In rats and Syrian hamsters, secretions of testicular androgens during prenatal and early postnatal life influence sexual differentiation and 'organize' many structures, including the penis, liver and brain (Grady et al., 1965; Swanson, 1970; Paup et al., 1974; Bardin and Caterall, 1981; Vomachka et al., 1981). There are no comparable data for Siberian hamsters, but it seems likely that permanent changes rendered during the organizational period profoundly affect penile responsiveness to androgens at puberty and in adulthood. In rats, prenatal androgen secretion modulates expression of androgen receptors in the embryonic urogenital tract (Bentvelsen et al., 1994) and influences differentiation of male internal and external genital structures (ImperatoMcGinley et al., 1992); during the latter part of fetal 
life and in early postnatal life the testes of SD Siberian hamsters may produce sufficient androgens to sensitize the penis to testosterone later in life.

The penile development of hamsters housed under long and short daylengths mirrors the developmental trajectories of the testes, androgen concentrations, FSH concentrations, body weight and other androgen-dependent tissues (Yellon and Goldman, 1984). Accelerated penile growth during puberty in Siberian hamsters is similar to that reported for rats (Gonzalez-Cadavid et al., 1991), rhesus monkeys (Plant, 1988) and men (Schonfeld, 1943; Williams-Ashman, 1990).

Prepubertal gonadectomy prevented penile development of hamsters in the present study, as reported for dogs and rodents (Beach and Levinson, 1950; Beach and Westbrook, 1968; Beach, 1970, 1984). Suppression of the postnatal androgen surge in infant rhesus monkeys also retards growth of the penis (Brown et al., 1999). Penile size and intromission success are highly positively correlated in male rats castrated at various ages (Beach and Holz, 1946). It is unknown whether the greatly reduced penile dimensions of prepubertal SD males would support male sexual behaviour.

Both prepubertal and postpubertal exogenous testosterone treatment profoundly affected the morphology of hamster penis, ventral prostate gland and seminal vesicle in the present study; testosterone or its metabolites was sufficient and may be necessary to induce and maintain adult tissue masses in hamsters housed under short and long daylengths at several ages (compare with Lerchl et al., 1993). However, in the present study there was virtually no impact of daylength on penile growth in castrated males treated with testosterone. Capsules filled with testosterone generated testosterone concentrations within the normal physiological range, but these values were maintained ostensibly for $24 \mathrm{~h}$ per day, whereas in intact hamsters, testosterone is increased for $4 \mathrm{~h}$ per day, with much lower concentrations sustained for the remainder of the day (Hoffmann and Nieschlag, 1977). Photoperiodic influences on penile growth may have been masked by the extended duration of testosterone treatment. In the present study, the effects of constant and prolonged exposure to testosterone early in life are reflected in the observed hypertrophy of the penes, seminal vesicles and ventral prostate glands.

Seminal vesicles of LD males castrated and provided with androgens in adulthood were substantially heavier than those of untreated intact controls. Hypertrophy of the penis was not as exaggerated as hypertrophy of the seminal vesicles. These results are congruent with continual growth of the seminal vesicles in rats and humans exposed to androgens in adulthood, and the cessation of penile growth on completion of puberty (Gonzalez-Cadavid et al., 1991). Exposure to endogenous gonadal steroids up to 80 days of age, in conjunction with supraphysiological durations of testosterone generated by capsules from 80 to 140 days of age, probably accounted for the $184 \%$ increase in mass of the seminal vesicles compared with that of intact males. The $87 \%$ decrease in ventral prostate gland and seminal vesicles masses in LD males castrated in adulthood contrasts with the $37 \%$ decrease in penile mass and the $29 \%$ decrease in body weight; evidently, the structural features of the penis, as reflected in overall mass in adulthood, are less dependent on androgens than are several other androgen-dependent tissues. Nevertheless, testicular secretions in adulthood contribute to the maintenance of high penile masses (Lerchl et al., 1993). A change in penile morphology after castration in adulthood is thought to contribute to a decline in sexual behaviour (Beach and Holtz, 1946).

In the present study, adult ventral prostate gland masses in intact SD males were fivefold greater than those of SD males castrated prepubertally, but still were only $20 \%$ of the comparable masses of LD intact animals. In contrast, there were virtually no differences in seminal vesicle masses among intact SD males and castrates. These results confirm and extend earlier studies of rats in which the threshold of responsiveness to androgens was lower in the ventral prostate gland than in seminal vesicles (Moore and Price, 1937, 1938). The SD testes of Siberian hamsters secrete sufficient androgen to produce slight trophic effects on the ventral prostate gland, but not on the seminal vesicles.

Testosterone concentrations in the present study were similar to values reported previously for $\mathrm{LD}$ and $\mathrm{SD}$ males (Jasnow et al., 2000; Bilbo et al., 2002). The relatively low testosterone concentrations of the SD sham-control males at 140 days of age reflect the slow and gradual development of hormone secretion by the testes, which lags behind testicular growth (Schlatt et al., 1995). The relatively high testosterone concentrations of the LD sham-control males were similar to concentrations obtained in a study in which LD males experienced restraint stress (Jasnow et al., 2000) and may have been affected by handling before surgical removal of tissues; however, these values were not observed in other similarly treated LD intact animals.

Given the robust effect of daylength on IGF-I in adult Syrian hamsters (Vaughan et al., 1994), the absence of differences in IGF-I concentrations as a function of daylength, or in prepubertal versus post-pubertal Siberian hamster males, is surprising. The finding that IGF-I concentration did not differ in prepubertal versus post-pubertal hamsters could reflect either infrequent or inappropriate time sampling. Alternatively, IGF-I may be a permissive factor that enables penile growth during long days; in the presence of increased androgen secretion, phallic growth might not require an increase in circulating IGF-I concentration above that present during short days. 
The authors thank M. J. Paul, A. S. Kauffman and C. Tuthill for invaluable technical assistance and D. A. Freeman for helpful comments on the manuscript. This research was supported by Grant 61171 from the National Institute of Mental Health and by grant IBN-0296060 from the National Science Foundation.

\section{References}

Anand S, Losee-Olson S, Turek FW and Horton TH (2002) Differential regulation of luteinizing hormone and follicle-stimulating hormone in male Siberian hamsters by exposure to females and photoperiod Endocrinology 143 2178-2188

Bardin CW and Catterall JF (1981) Testosterone: a major determinant of extragenital sexual dimorphism Science 211 1285-1294

Bartness TJ (1995) Short day-induced depletion of lipid stores is fat padand gender-specific in Siberian hamsters Physiology and Behavior $\mathbf{5 8}$ 539-550

Beach FA (1970) Coital behavior in dogs. VI. Long-term effects of castration upon mating in the male Journal of Comparative and Physiological Psychology 70 1-32

Beach FA (1984) Hormonal modulation of genital reflexes in male and masculinized female dogs Behavioral Neuroscience 98 325-332

Beach FA and Holz AM (1946) Mating behavior in male rats castrated at various ages and injected with androgen Journal of Experimental Zoology 101 91-142

Beach FA and Levinson G (1950) Effects of androgens on the glans penis and mating behavior of castrated male rats Journal of Experimental Zoology 114 159-169

Beach FA and Westbrook WH (1968) Dissociation of androgenic effects on sexual morphology and behavior in male rats Endocrinology 83 395398

Beach FA, Noble RG and Orndoff RK (1969) Effects of perinatal androgen treatment on responses of male rats to gonadal hormones in adulthood Journal of Comparative and Physiological Psychology 68 490-497

Bentvelsen FM, McPhaul MJ, Wilson JD and George FW (1994) The androgen receptor of the urogenital tract of the fetal rat is regulated by androgen Molecular and Cellular Endocrinology 105 21-26

Bilbo SD, Dhabhar FS, Viswanathan K, Saul A, Yellon SM and Nelson RJ (2002) Short day lengths augment stress-induced leukocyte trafficking and stress-induced enhancement of skin immune function Proceedings National Academy of Sciences USA 99 4067-4072

Brown GR, Nevison CM, Fraser HM and Dixson AF (1999) Manipulation of postnatal testosterone levels affects phallic and clitoral development in infant rhesus monkeys International Journal of Andrology 22 119-128

Butler AA and Le Roith D (2001) Minireview: tissue-specific versus generalized gene targeting of the IGF-I and IGF-Ir genes and their roles in insulin-like growth factor physiology Endocrinology 142 1685-1688

Chan K and Spencer EM (1998) Megakaryocytes endocytose insulin-like growth factor (IGF) I and IGF-binding protein-3: a novel mechanism directing them into alpha granules of platelets Endocrinology 139 $59-65$

Ebling FJ and Cronin AS (2000) The neurobiology of reproductive development Neuroreport 11 R23-R33

Foster DL, Ebling FJ and Claypool LE (1988) Timing of puberty by photoperiod Reproduction Nutrition Development 28 349-364

Gonzalez-Cadavid NF, Swerdloff RS, Lemmi CA and Rajfer J (1991) Expression of the androgen receptor gene in rat penile tissue and cells during sexual maturation Endocrinology 129 1671-1678

Gorman MR (2001) A plastic interval timer synchronizes pubertal development of summer- and fall-born hamsters American Journal of Physiology 281 R1613-R1623

Gorman MR and Zucker I (1998) Mammalian seasonal rhythms: new perspectives gained from the use of simulated natural photoperiods. In Biological Clocks: Mechanisms and Applications pp 195-204 Ed. Y Touitou. Elsevier Science, New York

Gorman MR, Goldman BD and Zucker I (2001) Mammalian photoperiodism. In Handbook of Behavioral Neurobiology pp 481-508 Eds J Takahashi, FW Turek and RY Moore. Plenum Press, New York
Grady KL, Phoenix CH and Young WC (1965) Role of the developing rat testis in differentiation of the neural tissues mediating mating behavior Journal of Comparative and Physiological Psychology 59 176-182

Hart BL (1974) Gonadal androgen and sociosexual behavior of male mammals: a comparative analysis Psychological Bulletin 81 383-400

Hoffmann K (1978) Effects of short photoperiods on puberty, growth and moult in the Djungarian hamster (Phodopus sungorus) Journal of Reproduction and Fertility 54 29-35

Hoffmann K (1982) The critical photoperiod in the Djungarian hamster, Phodopus sungorus. In Vertebrate Circadian Systems: Structure and Physiology pp 297-304 Eds J Aschoff, S Daan and G Groos. Springer, New York

Hoffmann K and Nieschlag E (1977) Circadian rhythm of plasma testosterone in the male Djungarian hamster (Phodopus sungorus) Acta Endocrinologica (Copenhagen) 86 193-199

Horton TH (1984a) Growth and maturation in Microtus montanus: effects of photoperiods before and after weaning Canadian Journal of Zoology 62 1741-1746

Horton TH (1984b) Growth and reproductive development of male Microtus montanus is affected by the prenatal photoperiod Biology of Reproduction 31 499-504

Imperato-McGinley J, Sanchez RS, Spencer JR, Yee B and Vaughan ED (1992) Comparison of the effects of the 5 alpha-reductase inhibitor finasteride and the antiandrogen flutamide on prostate and genital differentiation: dose-response studies Endocrinology 1311149 1156

Jasnow AM, Huhman KL, Bartness TJ and Demas GE (2000) Short-day increases in aggression are inversely related to circulating testosterone concentrations in male Siberian hamsters (Phodopus sungorus) Hormones and Behavior 38 102-110

Laron Z (1999) The essential role of IGF-I: lessons from the long-term study and treatment of children and adults with Laron syndrome Journal of Clinical Endocrinology and Metabolism 84 4397-4404

Laron Z and Klinger B (1998) Effect of insulin-like growth factor-I treatment on serum androgens and testicular and penile size in males with Laron syndrome (primary growth hormone resistance) European Journal of Endocrinology 138 176-180

Le Roith D, Bondy C, Yakar S, Liu JL and Butler A (2001a) The somatomedin hypothesis Endocrine Review 22 53-74

Le Roith D, Scavo L and Butler A (2001b) What is the role of circulating IGF-I? Trends in Endocrinology and Metabolism 12 48-52

Lerchl A, Sotiriadou S, Behre HM, Pierce J, Weinbauer GF, Kliesch S and Nieschlag E (1993) Restoration of spermatogenesis by follicle-stimulating hormone despite low intratesticular testosterone in photoinhibited hypogonadotropic Djungarian hamsters (Phodopus sungorus) Biology of Reproduction 49 1108-1116

Liu X, Lin CS, Spencer EM and Lue TF (2001) Insulin-like growth factor-I promotes proliferation and migration of cavernous smooth muscle cells Biochemical and Biophysical Research Communications $2801307-$ 1315

McMahon DR, Kramer SA and Husmann DA (1995) Micropenis: does early treatment with testosterone do more harm than good? Journal of Urology 154 825-829

Mauer MM and Bartness TJ (1995) A role for testosterone in the maintenance of seasonally appropriate body mass but not in lipectomy-induced body fat compensation in Siberian hamsters Obesity Research 3 31-41

Moore CR and Price D (1937) Some effects of synthetically prepared male hormone (androsterone) in the rat Endocrinology 21 313-329

Moore CR and Price D (1938) Some effects of testosterone and testosterone propionate in the rat Anatomical Record 71 59-78

Paup DC, Coniglio LP and Clemens LG (1974) Hormonal determinants in the development of masculine and feminine behavior in the female hamster Behavioral Biology 10 353-363

Plant TM (1988) Puberty in primates. In The Physiology of Reproduction pp 1763-1788 Eds E Knobil and JD Neill. Raven Press, New York

Prendergast BJ, Nelson RJ and Zucker I (2002) Mammalian seasonal rhythms: behavior and neuroendocrine substrates. In Hormones, Brain and Behavior pp 93-156 Eds DW Pfaff, Arnold AP, Etgen AM, Fahrback SD and Rubin RT. Elsevier Science, New York 
Schindelmeiser J, Aumuller G, Enderle-Schmitt U, Bergmann $M$ and Hoffmann K (1988) Photoperiodic influence on the morphology and the androgen receptor level of the ventral prostate gland and seminal vesicles of the Djungarian hamster (Phodopus sungorus) Andrologia 20 105-113

Schlatt S, De Geyter M, Kliesch S, Nieschlag E and Bergmann M (1995) Spontaneous recrudescence of spermatogenesis in the photoinhibited male Djungarian hamster, Phodopus sungorus. Biology of Reproduction 53 1169-1177

Schonfeld WA (1943) Primary and secondary sexual characteristics: study of their development in males from birth through maturity, with biometric study of penis and testes American Journal of Diseases of Children 65 535-549

Simpson SM, Follett BK and Ellis DH (1982) Modulation by photoperiod of gonadotrophin secretion in intact and castrated Djungarian hamsters Journal of Reproduction and Fertility 66 243-250

Swanson HH (1970) Effects of castration at birth in hamsters of both sexes on luteinization of ovarian implants, oestrous cycles and sexual behaviour Journal of Reproduction and Fertility 21 183-186

Vaughan MK, Buzzell GR, Hoffman RA, Menendez-Pelaez A and Reiter RJ (1994) Insulin-like growth factor-I in Syrian hamsters: interactions of photoperiod, gonadal steroids, pinealectomy, and continuous melatonin treatment Proceedings of the Society for Experimental Biology and Medicine 205 327-331

Vomachka AJ, Ruppert PH, Clemens LG and Greenwald GS (1981) Adult sexual behavior deficits and altered hormone levels in male hamsters given steroids during development Physiology and Behavior 26461 466

Williams-Ashman HG (1990) Enigmatic features of penile development and functions Perspectives in Biology and Medicine 33 335-374

Yellon SM and Goldman BD (1984) Photoperiod control of reproductive development in the male Djungarian hamster (Phodopus sungorus) Endocrinology 114 664-670

Received 30 August 2002.

First decision 1 November 2002.

Revised manuscript received 7 November 2002.

Accepted 3 December 2002. 